\title{
Quantitative Evaluation and Selection of Reference Genes for Quantitative RT-PCR in Mouse Acute Pancreatitis
}

\author{
Zhaoping Yan, ${ }^{1,2}$ Jinhang Gao, ${ }^{2}$ Xiuhe Lv, ${ }^{2}$ Wenjuan Yang, \\ Shilei Wen, ${ }^{2}$ Huan Tong, ${ }^{3}$ and Chengwei Tang ${ }^{2,3}$ \\ ${ }^{1}$ Department of Gastroenterology, Affiliated Hospital, Zunyi Medical College, Zunyi, Guizhou 563003, China \\ ${ }^{2}$ Division of Peptides Related with Human Diseases, State Key Laboratory of Biotherapy of Human Diseases, \\ West China Hospital, Sichuan University, Chengdu, Sichuan 610041, China \\ ${ }^{3}$ Department of Gastroenterology, West China Hospital, Sichuan University, Chengdu, Sichuan 610041, China
}

Correspondence should be addressed to Chengwei Tang; shcqcdmed@163.com

Received 23 November 2015; Revised 19 January 2016; Accepted 7 February 2016

Academic Editor: Christian Guelly

Copyright (C) 2016 Zhaoping Yan et al. This is an open access article distributed under the Creative Commons Attribution License, which permits unrestricted use, distribution, and reproduction in any medium, provided the original work is properly cited.

\begin{abstract}
The analysis of differences in gene expression is dependent on normalization using reference genes. However, the expression of many of these reference genes, as evaluated by quantitative RT-PCR, is upregulated in acute pancreatitis, so they cannot be used as the standard for gene expression in this condition. For this reason, we sought to identify a stable reference gene, or a suitable combination, for expression analysis in acute pancreatitis. The expression stability of 10 reference genes (ACTB, GAPDH, 18sRNA, TUBB, B2M, HPRT1, UBC, YWHAZ, EF-1 $\alpha$, and RPL-13A) was analyzed using geNorm, NormFinder, and BestKeeper software and evaluated according to variations in the raw $\mathrm{Ct}$ values. These reference genes were evaluated using a comprehensive method, which ranked the expression stability of these genes as follows (from most stable to least stable): RPL-13A, YWHAZ > HPRT1 > GAPDH > UBC $>$ EF- $1 \alpha>18$ sRNA $>$ B2M $>$ TUBB $>$ ACTB. RPL-13A was the most suitable reference gene, and the combination of RPL-13A and YWHAZ was the most stable group of reference genes in our experiments. The expression levels of ACTB, TUBB, and B2M were found to be significantly upregulated during acute pancreatitis, whereas the expression level of 18sRNA was downregulated. Thus, we recommend the use of RPL-13A or a combination of RPL-13A and YWHAZ for normalization in qRT-PCR analyses of gene expression in mouse models of acute pancreatitis.
\end{abstract}

\section{Introduction}

Quantitative real-time RT-PCR has become more popular than endpoint RT-PCR for high-throughput and accurate expression profiling of selected genes due to its higher sensitivity, specificity, and broader quantification range [1-3]. However, it is difficult to include the same amount of RNA for samples from different tissues because of differences in cell content or composition of the inflammatory organ [4], differing degrees of RNA degradation $[5,6]$, and differences in the efficiency of reverse transcription $[1-3,7,8]$. Although a number of common methods are used for normalization, such as adjustment to the input of total RNA [1-3, 7, 8], rRNA [9], or mRNA [10, 11], these are susceptible to impacts of experimental treatments $[8,12]$. Thus, the normalization of a reference gene is currently the most accepted method to correct for minor variations in fluctuating samples $[1-3,7-$ $9,13]$.

Selection of an appropriate reference gene can reduce differences between specimens to reveal a tangible difference in the specific expression of target genes, and the expression of an ideal reference gene should remain stable across tissues and cells under various experimental conditions [1-3, 7$9,13]$. Recently, a large number of reports have demonstrated that these classic reference genes (e.g., beta-actin ACTB, glyceraldehyde-3-phosphate dehydrogenase GAPDH, and 18s ribosomal RNA 18sRNA) show variations in expression that may be influenced by experimental treatments and are therefore unsuitable for normalization [1-3, 7-11, 13]. Indeed, over $90 \%$ of RNA transcription analyses have used only one reference gene [14]. Moreover, a single reference gene may not be applied to standardize the exact amount of RNA 
input, especially for tissues $[9,15]$, due to fluctuations in the expression of this reference gene [1-3,7-9, 13-16]. Ubiquitous reference genes in diverse mammalian expression studies were also not applicable $[9,13,14,17]$. However, to detect precise changes between different samples of pancreatic tissue, these classical housekeeping genes are not suitable reference genes for qRT-PCR because of the considerable variation in their expression $[13,14,17]$. Thus, the verification of optimal reference genes for qPCR in pancreatic tissues during acute pancreatitis is urgently needed.

But the identification of an optimal reference gene can be a difficult task for the investigator [2]. Also, due to the composition $[18,19]$ and size $[20,21]$ of the organ, no constant reference genes have been identified for these studies. The same problem has been reported in pancreatic tissues during acute pancreatitis, when a large number of leucocytes infiltrate into pancreatic tissues and many pancreatic acinar cells undergo necrosis. Because the severity of acute pancreatitis is related not only to activated trypsinogen but also to the amount and type of leucocytes infiltrated, the subsequent necrosis of pancreatic tissues (including RNA degradation) is the result of enzymes released from leucocytes and damaged pancreatic acinar cells. Thus, it was hypothesized that, due to RNA degradation in pancreatic inflammatory tissue and the severity of acute pancreatitis, reference gene expression stability would be affected by the quality of RNA obtained from these tissues $[5,6]$.

In studies of caerulein-induced murine acute pancreatitis, ACTB [22-28], GAPDH [18, 19, 28-30], 18sRNA [21, 31, $32]$, beta-2 microglobulin (B2M) [4, 33], and hypoxanthine phosphoribosyltransferase 1 (HPRT1) [34] have been frequently used as reference genes for comparison of mRNA transcription in pancreatic tissue. In fact, because of lower sensitivity and specificity of RT-PCR or northern blot analysis and a large range variation in target mRNA expression, no erroneous conclusions were reported, even if the reference gene expression fluctuated. Jesnowski and colleagues found that ribosomal protein L13A (RPL-13A) is a reliable standard for chronic pancreatitis [35]. And RPL-13A and ubiquitin C (UBC) were shown to be the most stable reference genes in a variety of human cells and tissues $[16,36]$, while YWHAZ and HPRT1 were the most stable reference genes in partial degradation samples from chronic rhinosinusitis [6].

The current study investigated several common housekeeping genes (ACTB, GAPDH, and 18sRNA), genes commonly used as internal controls, including beta-tubulin (TUBB), UBC, and eukaryotic translational elongation factor 1 alpha $(\mathrm{EF}-1 \alpha)$, and genes that were previously reported as stable reference genes such as $\mathrm{B} 2 \mathrm{M}[4,33]$ and tyrosine 3-monooxygenase/tryptophan 5-monooxygenase activation protein, zeta polypeptide (YWHAZ) [6] during inflammation and infection [37], HPRT1 for cerulein-induced acute pancreatitis mouse model [34], and RPL13A for the patient with acute pancreatitis [35] (see Supplementary Table 3 in Supplementary Material available online at http://dx.doi.org/10.1155/2016/8367063).

This study is the first to perform systematic examination of potential reference genes in pancreatic tissues from mice with caerulein- or LPS-induced acute pancreatitis. We aimed to identify reference genes that were not regulated by caerulein or LPS, and our results should help investigators by providing suitable reference genes for analyses at different time points following the induction of acute pancreatitis.

\section{Materials and Methods}

2.1. Animal Model. All experiments were approved by the animal ethics committee of Sichuan University and performed in accordance with established International Guiding Principles for Animal Research. 48 BalB/C mice were fasted from solid food for $12-16 \mathrm{~h}$ (but provided with water ad libitum) and were then assigned randomly to either the control group (that received 6 times intraperitoneal natural saline injections), caerulein group (that received 6 times intraperitoneal injections of $50 \mu \mathrm{g} / \mathrm{kg} / \mathrm{h}$ caerulein, C9026, Sigma Aldrich) [38], or caerulein + LPS group (that received 6 times intraperitoneal injections of $50 \mu \mathrm{g} / \mathrm{kg} / \mathrm{h}$ caerulein, with $10 \mathrm{mg} / \mathrm{kg}$ LPS at the last injection, E. Coli O111:B4, Sigma Aldrich) [39, 40]. At $1 \mathrm{~h}, 3 \mathrm{~h}, 6 \mathrm{~h}, 9 \mathrm{~h}, 24 \mathrm{~h}$, and $48 \mathrm{~h}$ after the final treatment with caerulein or LPS, six mice (each group) were laparotomized under anesthesia by intraperitoneal administration of $4 \%$ chloral hydrate $(0.2 \mathrm{~mL})$. The six mice in the control and the caerulein group were treated similarly at $3 \mathrm{~h}$ and $6 \mathrm{~h}$ after the final injection, respectively. Samples of the pancreas were quickly removed, fresh frozen in liquid nitrogen, and stored at $-80^{\circ} \mathrm{C}$ [41]. Other samples of the pancreas were fixed in $4 \% \mathrm{v} / \mathrm{v}$ neutral phosphate-buffered paraformaldehyde and then embedded in paraffin. Sections were routinely sliced and stained with hematoxylin and eosin for morphologic analysis by light microscopy.

2.2. RNA Isolation and Reverse Transcription. Approximately $20 \mathrm{mg}$ of pancreatic tissue was ground into tissue powder in liquid nitrogen, and RNA was then extracted with RNAiso reagent (Takara). Briefly, after RNA was pelleted by centrifugation $\left(10000 \mathrm{~g}\right.$ for $15 \mathrm{~min}$ at $\left.4^{\circ} \mathrm{C}\right)$, the pellet was washed in $75 \% \mathrm{v} / \mathrm{v}$ ethanol twice. The amount of RNA was determined spectrophotometrically by using Gene Quant100 (GE, USA) instrument; and the integrity was verified by Gold view staining of $18 \mathrm{~s}$ and $28 \mathrm{~s}$ rRNA bands on a $1 \%$ denaturing agarose gel. After incubation with DNase I (Roche) at $37^{\circ} \mathrm{C}$ for 30 minutes, RNA ( $3 \mu \mathrm{g}$ ) was reverse-transcribed with random primers using the RevertAid First Stand cDNA Synthesis Kit (Thermo Scientific, 1622).

2.3. Quantitative RT-PCR. Quantitative RT-PCR analysis was performed using the primers shown in Table 1. And qRT-PCR was performed with the BioRad CFX96 Sequence Detection System by using the SYBR Green PCR Master Mix (Qiagen). The PCR reaction consisted of $10 \mu \mathrm{L}$ of SYBR Green PCR Master Mix, $1 \mu \mathrm{L}$ of forward and reverse primers $(4 \mu \mathrm{M})$, and $1 \mu \mathrm{L}$ of template cDNA in a total volume of $20 \mu \mathrm{L}$. Cycling was performed using the conditions specified in the BioRad CFX96 Manager Version Software 3.1, consisting of $5 \mathrm{~min}$ at $95^{\circ} \mathrm{C}, 10 \mathrm{sec}$ at $95^{\circ} \mathrm{C}$, and $30 \mathrm{sec}$ at $60^{\circ} \mathrm{C}$, followed by 40 rounds of $10 \mathrm{sec}$ at $95^{\circ} \mathrm{C}$ and $30 \mathrm{sec}$ at $60^{\circ} \mathrm{C}$. Triplicates of all reactions were analyzed. Each assay also included three blanks. 
TABLE 1: Primer sequences for reference genes.

\begin{tabular}{|c|c|c|c|c|}
\hline Gene symbol & Primer & NCBI accession numbers & PCR efficiency & Amplicon length \\
\hline \multirow{2}{*}{ ACTB } & F: TGACGTTGACATCCGTAAAG & \multirow{2}{*}{ NM_007393.3 } & \multirow{2}{*}{$90.9 \%$} & \multirow{2}{*}{$143 \mathrm{bp}$} \\
\hline & R: GAGGAGCAATGATCTTGATCT & & & \\
\hline \multirow{2}{*}{ GAPDH } & F: GGTGAAGGTCGGTGTGAACG & \multirow{2}{*}{ NM_001289726.1 } & \multirow{2}{*}{$101.9 \%$} & \multirow{2}{*}{$233 \mathrm{bp}$} \\
\hline & R: CTCGCTCCTGGAAGATGGTG & & & \\
\hline \multirow{2}{*}{ 18sRNA } & F: GTAACCCGTTGAACCCCATT & \multirow{2}{*}{ NR_003278.3 } & \multirow{2}{*}{$95.1 \%$} & \multirow{2}{*}{$151 \mathrm{bp}$} \\
\hline & R: CCATCCAATCGGTAGTAGCG & & & \\
\hline \multirow{2}{*}{$\mathrm{B} 2 \mathrm{M}$} & F: GCTATCCAGAAAACCCCTCAA & \multirow{2}{*}{ NM_009735.3 } & \multirow{2}{*}{$96.2 \%$} & \multirow{2}{*}{$300 \mathrm{bp}$} \\
\hline & R: CATGTCTCGATCCCAGTAGACGGT & & & \\
\hline \multirow{2}{*}{ RPL13A } & F: GAGGTCGGGTGGAAGTACCA & \multirow{2}{*}{ NM_009438.5 } & \multirow{2}{*}{$95.2 \%$} & \multirow{2}{*}{$71 \mathrm{bp}$} \\
\hline & R: TGCATCTTGGCCTTTTCCTT & & & \\
\hline \multirow{2}{*}{$\mathrm{EF} 1 \alpha$} & F: CTGAACCATCCAGGCCAAAT & \multirow{2}{*}{ NM_010106.2 } & \multirow{2}{*}{$98.0 \%$} & \multirow{2}{*}{$60 \mathrm{bp}$} \\
\hline & R: GGCTGTGTGACAATCCAG & & & \\
\hline \multirow{2}{*}{ UBC } & F: GCCCAGTGTTACCACCAAGA & \multirow{2}{*}{ NM_019639.4 } & \multirow{2}{*}{$98.6 \%$} & \multirow{2}{*}{$104 \mathrm{bp}$} \\
\hline & R: CCCATCACACCCAAGAACA & & & \\
\hline \multirow{2}{*}{ HPRT1 } & F: CCAGCGTCGTGATTAGCG & \multirow{2}{*}{ NM_013556.2 } & \multirow{2}{*}{$96.3 \%$} & \multirow{2}{*}{$222 \mathrm{bp}$} \\
\hline & R: CCAGCAGGTCAGCAAAGAAC & & & \\
\hline \multirow{2}{*}{ YWHAZ } & F: CAGTAGATGGAGAAAGATTTGC & \multirow{2}{*}{ NM_001253807 } & \multirow{2}{*}{$97.4 \%$} & \multirow{2}{*}{92 bp } \\
\hline & R: GGGACAATTAGGGAAGTAAGT & & & \\
\hline TUBB & F: CGGCAACTATGTAGGGGACT & NM 1780143 & $967 \%$ & $194 \mathrm{bn}$ \\
\hline & R: CAGCACCACTCTGACCAAAG & & & \\
\hline
\end{tabular}

2.4. Evaluation of the Stability of Candidate Reference Genes. To evaluate the stability of candidate reference genes expressed as Ct values, we used the software provided by BioRad (version 3.1), which was consistent with the statistical algorithm of geNorm. This program calculated the $M$ value of each candidate gene pairwise. After stepwise exclusion of the gene with the highest $M$ value, the remaining genes were recalculated for $M$ values in turn. In the end, the two genes with the lowest average $M$ value were accepted. This iterative process was enabled to rank these candidate genes based on their stability of expression [16].

NormFinder is another Excel-Based Visual Basic for Applications used to identify the optimal reference gene [42].

BestKeeper was used as an Excel-based software tool to determine the best suitable reference genes using pairwise correlation analysis of candidate reference genes [43].

The comparative $\Delta \mathrm{Ct}$ method was performed to assess the most stable reference genes by comparing relative expression within each tissue sample or each treatment [44].

The stability of a gene was measured by the mean of standard deviation values derived from comparisons among reference genes $[45,46]$.

2.5. Statistical Analysis. Comparison of variances for the expression of distinct genes was used to analyze the significance of differences between control and treated groups using one-way analysis of variance (ANOVA) (GraphPad Prisms Software version 6, San Diego, CA, USA). A $p$ value $<0.05$ was considered statistically significant.

\section{Results}

3.1. Acute Pancreatitis Induced by Caerulein or LPS. All mice given peritoneal injections of caerulein and/or LPS survived. By visual inspection, the volume of the pancreas in the treatment groups was larger than that in the control group, of which treated was pale. Glandular swelling, spacing broadening, necrosis of acinar cells, infiltration of inflammatory cells, and hemorrhage were observed by light microscopy in acute pancreatitis mice. No pathological changes were observed in the control mice (Figure 1).

3.2. Total RNA Quality. Cut-off values of $>1.8$ (OD260/280) and $>2.0$ (OD260/230) were used as quality measures of total RNA samples. RNA integrity analysis, using denaturing gel electrophoresis, showed distinct and sharp 28s and 18s RNA bands. To prove contaminating genomic DNA, untranscribed (RT-minus control) RNA samples were used.

3.3. Expression Profiles of Candidate Reference Genes. The transcript abundance of commonly used reference genes was analyzed in pancreatic samples by direct comparison of their $\mathrm{Ct}$ values, with a precondition of an equal quantity of total RNA and RNA degradation. The data of qRT-PCR reactions (Table 1) was in line with MIQE guidelines [47]. And melting curve analysis revealed that all primer pairs amplified a single PCR product. Figure 3 shows the mean Ct values of 10 selected genes. The highest variation was observed for ACTB, while RPL-13A showed the lowest dispersion, and YWHAZ showed higher dispersion than RPL-13A only. 


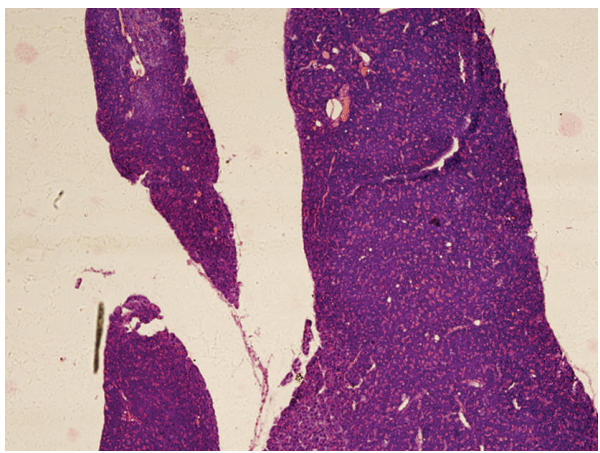

(a)

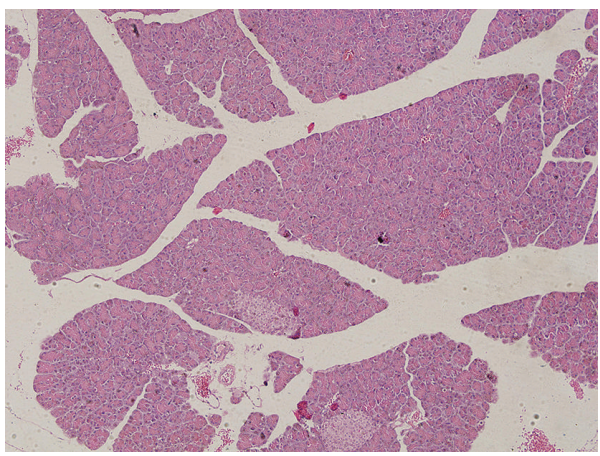

(b)

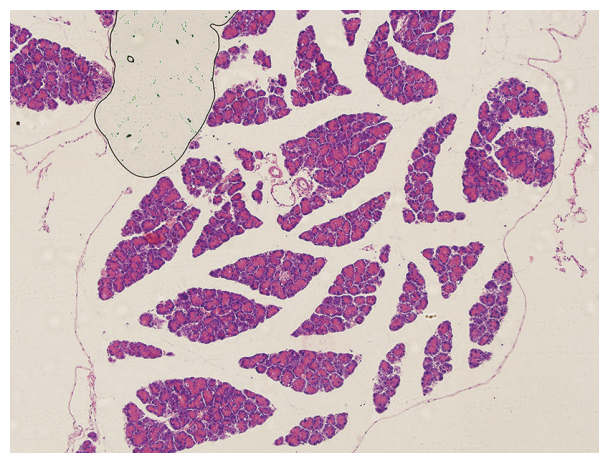

(c)

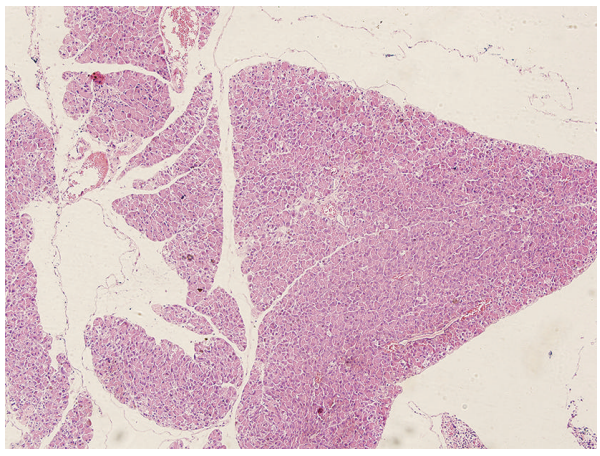

(d)

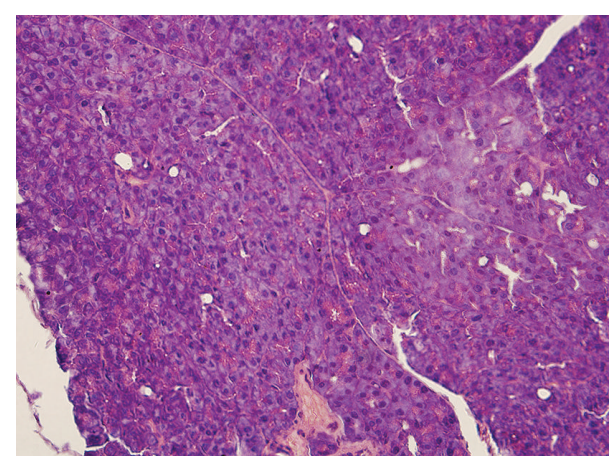

(e)

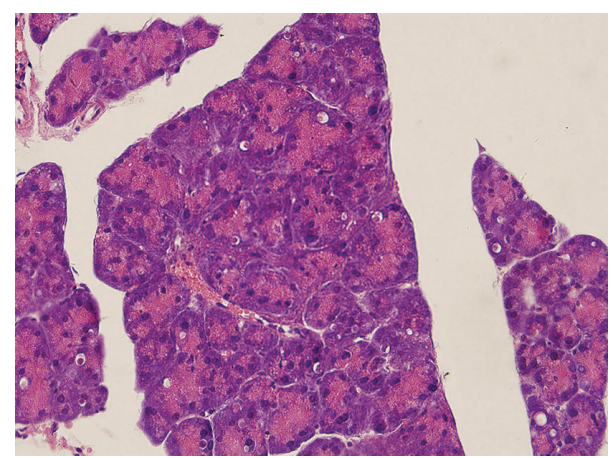

(f)

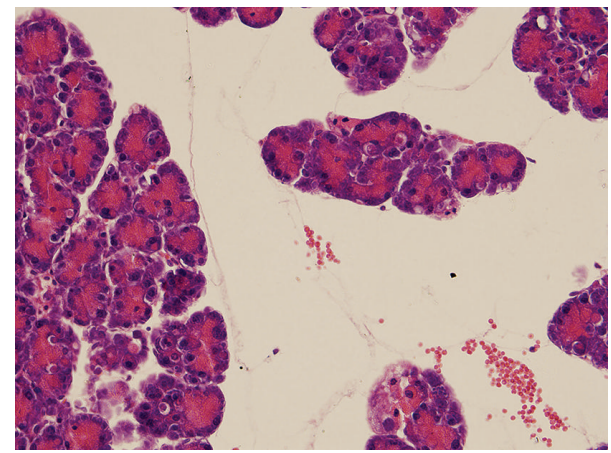

(g)

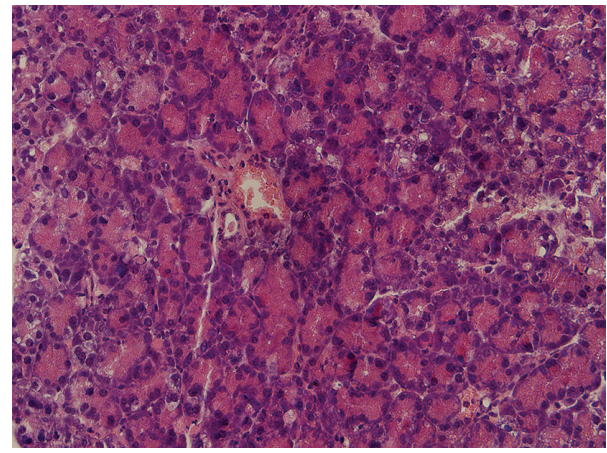

(h)

Figure 1: Histological changes in the pancreas of treated mice. HE stain, from (a) to (d): $\times 100$; from (e) to (h): $\times 400$. (a/e) Control: normal pancreas; (b/f) MAP $3 \mathrm{~h}$; (c/g) SAP $3 \mathrm{~h}$; (d/h) SAP $48 \mathrm{~h}$. 
TABLE 2: Comprehensive ranking of reference genes.

\begin{tabular}{|c|c|c|c|c|c|}
\hline Ranking order & geNorm & NormFinder & BestKeeper & Variation of raw $\mathrm{Ct}$ values & $\begin{array}{c}\text { Comprehensive ranking } \\
\text { (mean rank value) }\end{array}$ \\
\hline 1 & $\begin{array}{l}\text { RPL-13A } \\
\text { YWHAZ }\end{array}$ & YWHAZ & RPL-13A & RPL-13A & $\begin{array}{c}\text { RPL-13A } \\
\text { YWHAZ } \\
1.414 \\
\end{array}$ \\
\hline 2 & HPRT1 & GAPDH & YWHAZ & YWHAZ & $\begin{array}{c}\text { HPRT1 } \\
3.080\end{array}$ \\
\hline 3 & GAPDH & UBC & HPRT1 & HPRT1 & $\begin{array}{c}\text { GAPDH } \\
4.242 \\
\end{array}$ \\
\hline 4 & $\mathrm{EF}-1 \alpha$ & RPL-13A & 18sRNA & $\mathrm{EF}-1 \alpha$ & $\begin{array}{l}\text { UBC } \\
4.786 \\
\end{array}$ \\
\hline 5 & $\mathrm{UBC}$ & HPRT1 & $\mathrm{EF}-1 \alpha$ & UBC & $\begin{array}{c}\text { EF- } 1 \alpha \\
5.180\end{array}$ \\
\hline 6 & $18 s R N A$ & $\mathrm{~B} 2 \mathrm{M}$ & GAPDH & 18sRNA & $\begin{array}{c}18 \text { sRNA } \\
6.160\end{array}$ \\
\hline 7 & $\mathrm{~B} 2 \mathrm{M}$ & TUBB & UBC & $\mathrm{B} 2 \mathrm{M}$ & $\begin{array}{l}\mathrm{B} 2 \mathrm{M} \\
6.694\end{array}$ \\
\hline 8 & TUBB & АСТВ & $\mathrm{B} 2 \mathrm{M}$ & TUBB & $\begin{array}{l}\text { TUBB } \\
7.969 \\
\end{array}$ \\
\hline 9 & ACTB & $\mathrm{EF}-1 \alpha$ & TUBB & GAPDH & $\begin{array}{c}\text { ACTB } \\
9.212 \\
\end{array}$ \\
\hline 10 & - & 18sRNA & ACTB & ACTB & - \\
\hline
\end{tabular}

3.4. Caerulein and LPS Affect the Expression Level of Reference Genes. Pancreatic mRNA expression differences were investigated for 10 reference genes in conditions without stimulation or following stimulation with caerulein or LPS (Figure 2). The mRNA expression of candidate reference genes is indicated by the raw $\mathrm{Ct}$ value at discrete time points after caerulein or LPS peritoneal injection.

Distributions of raw $\mathrm{Ct}$ values for each reference gene were visualized as column-means and error bars. Columnmeans show the distributions of raw $\mathrm{Ct}$ values (arithmetic means $\pm \mathrm{SD}, n=4-6)$ for each of the genes tested (MAP $3 \mathrm{~h}$ : mild acute pancreatitis induced by caerulein, at $3 \mathrm{~h}$ after the last caerulein injection; SAP $1 \mathrm{~h}$ : severe acute pancreatitis induced by caerulein and LPS, at $1 \mathrm{~h}$ after the last caerulein and LPS injection; SAP $3 \mathrm{~h}: 3 \mathrm{~h}$ after the last caerulein and LPS injection; SAP $6 \mathrm{~h}: 6 \mathrm{~h}$ after the last caerulein and LPS injection; SAP $9 \mathrm{~h}: 9 \mathrm{~h}$ after the last caerulein and LPS injection; SAP $24 \mathrm{~h}: 24 \mathrm{~h}$ after the last caerulein and LPS injection; SAP $48 \mathrm{~h}: 48 \mathrm{~h}$ after the last caerulein and LPS injection).

3.5. Stability of Reference Gene Expression. Reference genes were then ranked by stepwise exclusion of the gene with the highest $M$ value (Figure 3). Based on these $M$ values, the most stable reference genes with the lowest $M$ values were RPL-13A and YWHAZ, while the most unstable was ACTB. According to the algorithm of NormFinder, the most stable reference gene was YWHAZ, and the best combination of two reference genes was YWHAZ and GAPDH (Figure 3). The data obtained with BestKeeper software showed that RPL-13A was the optimal reference gene, with RPL-13A and YWHAZ as the most appropriate combination, which was similar to the results from the geNorm algorithm (Figure 3).

Average expression stability values of candidate reference genes using geNorm, NormFinder, and BestKeeper analysis were performed across all samples. The gene stability value is based on the average pairwise variation between all tested reference genes. The expression stability of genes indicates the least stable (Figure 3(a)) to the most stable (Figure 3(b)) gene.

Distribution of qRT-PCR quantification cycle values for candidate reference genes was visualized as column means and error bars (Figure 3(b)). The mRNA expression of 10 candidate reference genes is shown for mice in the control and experiment groups treated with caerulein and/or LPS. Box and whiskers represent the variance in expression of a particular gene among the specimens. The values are expressed as the mean $\pm \mathrm{SD}$.

3.6. Final Ranking of Candidate Reference Genes. Considering the ranking results from the four algorithms, we obtained a comprehensive ranking of reference genes (Table 2) [45, 46]. The three most stable reference genes were RPL-13A, YWHAZ, and HPRT1, and the least stable reference genes were $\mathrm{ACTB}, \mathrm{TUBB}$, and B2M.

\section{Discussion}

In this study, we evaluated 10 reference genes using qPCR in 45 pancreatic tissues from mice with caerulein- or LPSinduced acute pancreatitis. 

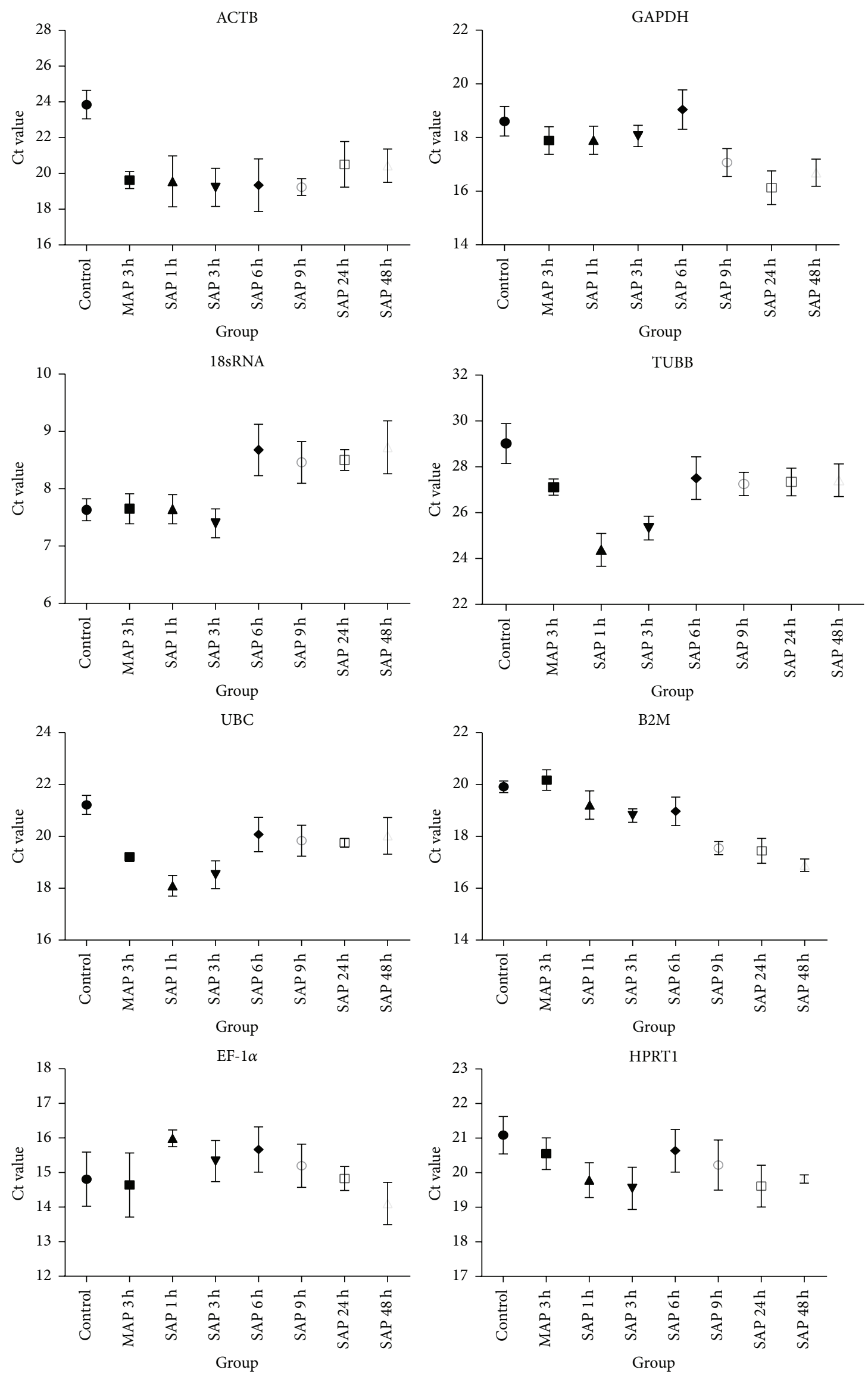

Figure 2: Continued. 

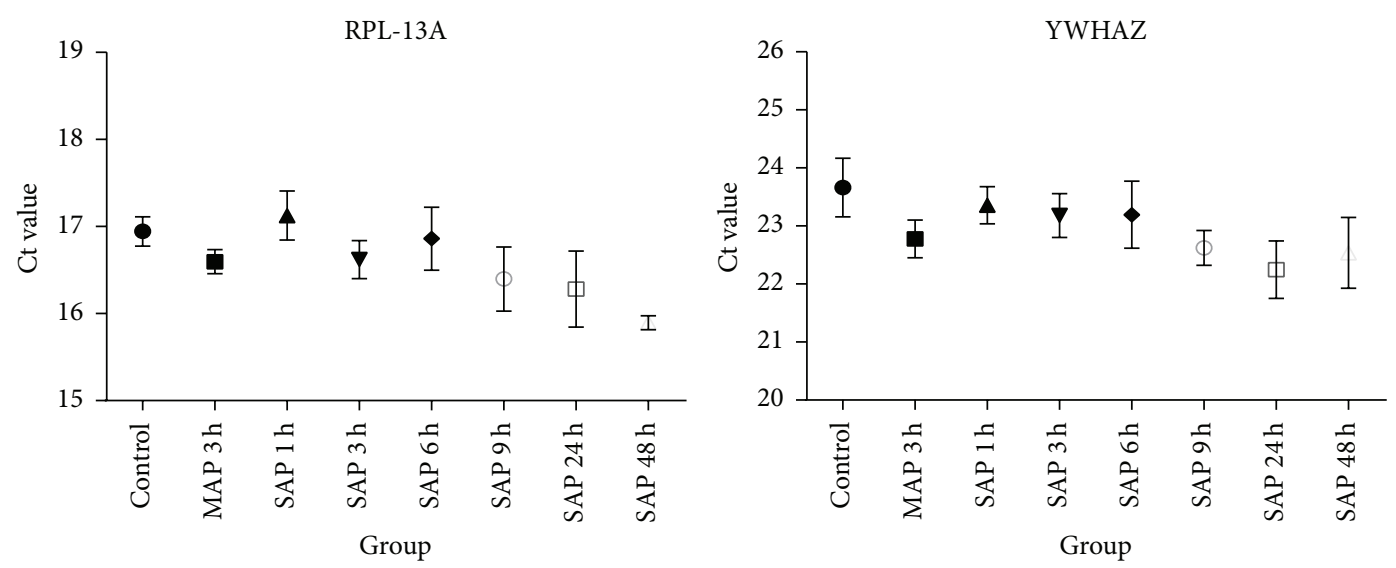

FIGURE 2: Effect of caerulein or LPS stimulation on reference gene expression.
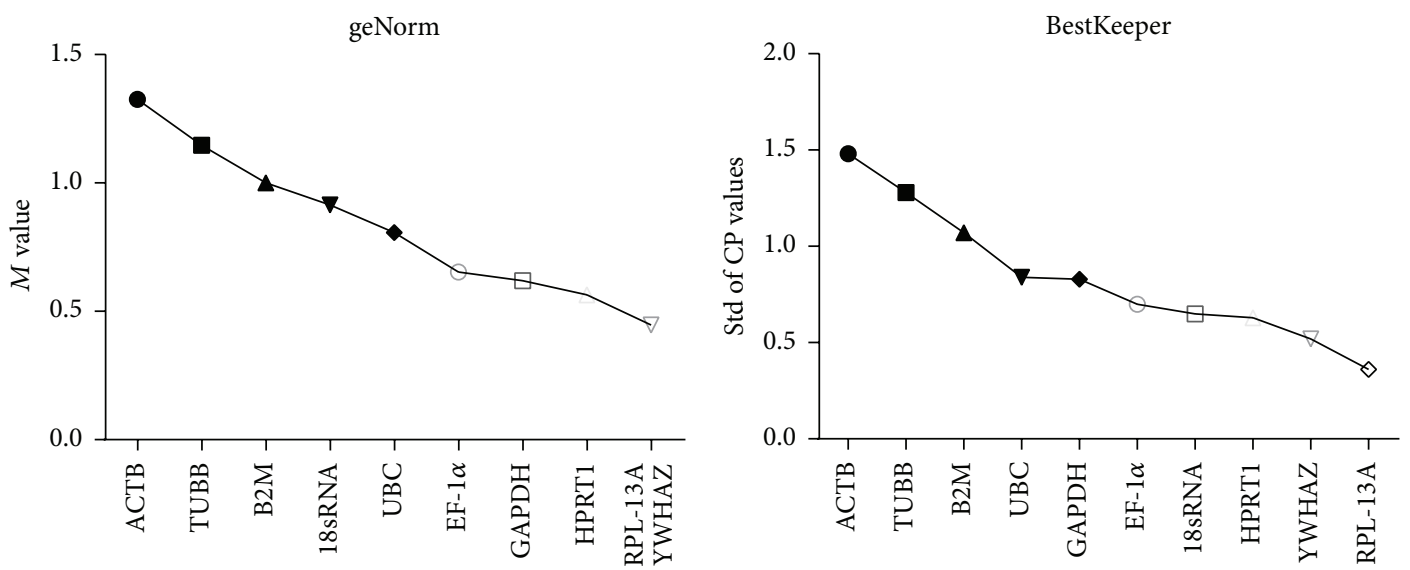

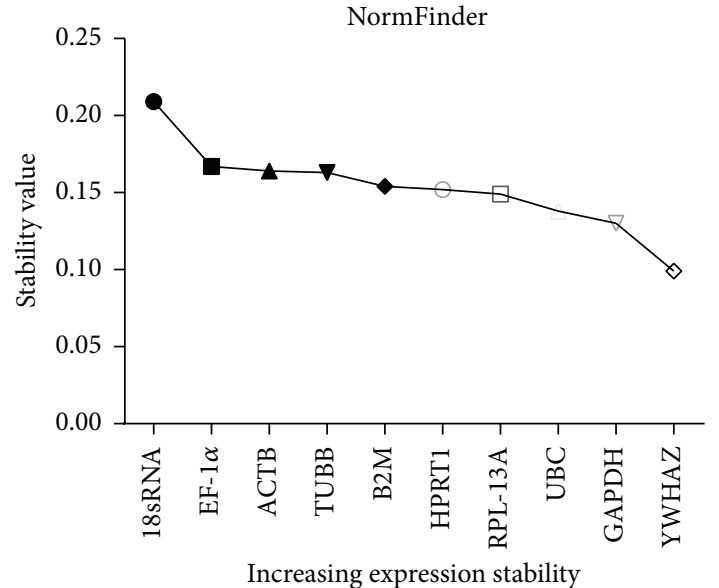

(a)

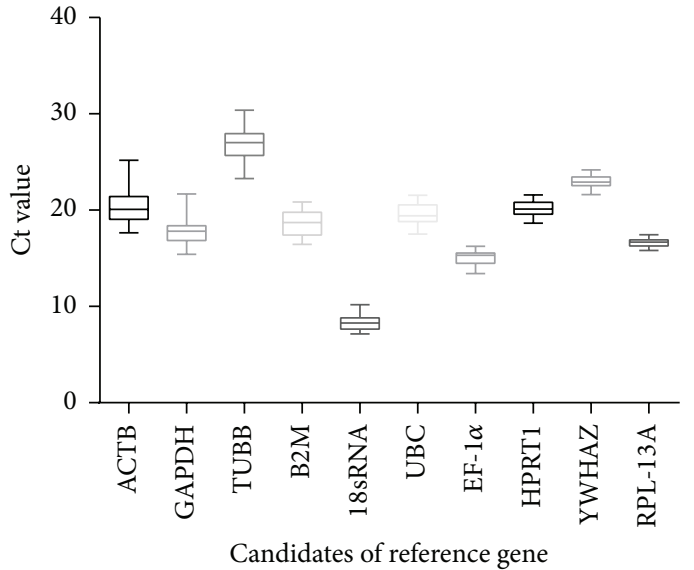

(b)

FIGURE 3: Expression stability values of candidate reference genes during acute pancreatitis.

The level of ACTB mRNA in pancreatic tissues stimulated by caerulein or LPS was increased significantly compared to that in the control group. Yuan and colleagues found that the level of ACTB mRNA in rat pancreatic tissues increased continuously after caerulein infusion, and immunostaining for ACTB was observed along the membrane of large cytoplasmic vacuoles in pancreatic acinar cells [48]. Furthermore, repeated experimental data suggest that ACTB is not a suitable reference gene under certain conditions [49-51]. Unfortunately, many researchers have ignored these data and 
misinterpreted the increased level of ACTB as differences among samples or RNA inputs [22, 24-28].

We observed a significant difference among TUBB mRNA expressions in pancreatic tissues from the control group MAP and SAP group. Similar to ACTB, TUBB was not an appropriate reference gene because its expression fluctuated with the pathophysiological process of acute pancreatitis [52].

GAPDH mRNA expression in pancreatic tissue did not vary in animals with MAP induced by caerulein only and in those in the early phase of SAP following treatment with caerulein and LPS, although this expression increased in the later phase (SAP $9 \mathrm{~h}, \mathrm{SAP} 24 \mathrm{~h}$, and SAP $48 \mathrm{~h}$ ). This result is consistent with previous reports $[53,54]$ and draws a distinction between Yuan et al.'s results, where GAPDH mRNA increased after $6 \mathrm{~h}$ of caerulein treatment [48]. Although GAPDH is a suitable reference gene in mouse caeruleininduced acute pancreatitis $[18,19,29,30]$ and during the early phase of mouse SAP induced by caerulein and LPS, the variation in GAPDH mRNA expression should not be ignored, which probably results from glucose metabolism disturbance in the later phase of the illness [54].

18sRNA expression in pancreatic tissues did not vary during MAP induced by caerulein only and during the early phase (within $3 \mathrm{~h}$ after LPS injection) of SAP induced by caerulein and LPS, which is consistent with Yamada et al.s reports [20]. Thus, with very high abundance and resistance to degradation compared to other genes [5], 18sRNA may have lower variance as a reference gene in pancreatic tissue. However, 18sRNA expression in pancreatic tissue was downregulated in the later phase (6-48 h after LPS injection), which is consistent with the lower level of 18 sRNA reported in pancreatic carcinoma compared to normal pancreatic tissue [51]. Similar to GAPDH, 18sRNA may represent a suitable reference gene in mouse caerulein-induced acute pancreatitis $[21,31,32]$, or the early phase (within $3 \mathrm{~h}$ after LPS injection) of mouse acute pancreatitis by caerulein and LPS. However, 18sRNA was not a suitable reference gene for analyses of the later phase of SAP.

The mRNA expression of B2M and HPRT1 in pancreatic tissues remained constant between the control group and MAP group, which indicated that B2M and HPRT1 are appropriate reference genes for caerulein-induced acute pancreatitis $[4,34]$. However, in the SAP groups, the level of B2M mRNA was increased and especially high at discrete time points after LPS injection (the level of SAP $9 \mathrm{~h}$ was higher than that of SAP $6 \mathrm{~h}$ ). Thus, B2M was not a suitable reference gene for SAP. Because of its enriched expression in immunocytes, variation in B2M mRNA expression may correspond to the infiltration of leukocytes into pancreatic tissues at different stages of acute pancreatitis, according to the cell composition in the inflammatory tissue $[55,56]$.

RPL13A was shown to be the most stable reference gene in a variety of human cells and tissues [16, 35, 36], verified in other experiments [57-59]. Nevertheless, the level of RPL-13A mRNA expression among groups was unstable, even if such changes were small. Due to the unavoidable degradation of RNA by enzymes in pancreatic tissue during acute pancreatitis, YWHAZ should serve as a suitable reference gene. However, the level of YWHAZ mRNA expression showed slight fluctuations among and within groups.

Software analysis using the geNorm algorithm identified RPL-13A and YWHAZ as the most stable genes, followed by HPRT1 and GAPDH. The ranking order presented was similar to that provided using BestKeeper and based on the variation in raw $\mathrm{Ct}$ values, except for GAPDH showing a lower rank. However, the NormFinder analysis identified YWHAZ as the best reference gene with the highest expression stability, along with GAPDH, UBC, and RPL-13A. Interestingly, with the top rank in other algorithms, RPL-13A was ranked as the fourth best reference gene by NormFinder. Thus, the ranking order of RPL-13A by NormFinder was not consistent with the results of other algorithms. And there was no obvious modification of the ranking order of YWHAZ. So, based on the combined results of all algorithms, the comprehensive ranking presented RPL-13A and YWHAZ as the optimal reference genes. These reference genes were evaluated using a comprehensive method, which ranked the expression stability of these genes as follows (from most stable to least stable): RPL-13A, YWHAZ > HPRT1 > GAPDH > $\mathrm{UBC}>\mathrm{EF}-1 \alpha>18$ sRNA $>$ B2M $>$ TUBB $>$ ACTB. RPL-13A was the most suitable reference gene, and the combination of RPL-13A and YWHAZ was the most stable group of reference genes in our experiments.

\section{Conclusions}

As discussed above, we observed variations in the expression of commonly used reference genes in response to injection with caerulein and LPS, and no absolutely stable reference gene was identified in pancreatic tissue from animals with acute pancreatitis. Nevertheless, RPL-13A was the most suitable reference gene, while RPL-13A and YWHAZ were identified as the best combination of reference genes. 


\section{Disclosure}

The funders had no role in study design, data collection and analysis, decision to publish, or preparation of the paper.

\section{Conflict of Interests}

The authors declare no conflict of interests.

\section{Authors' Contribution}

Zhaoping Yan, Jinhang Gao, and Wenjuan Yang developed the study idea, concept, and the overall study design in addition to planning and coordinating the study. Zhaoping Yan performed the plans and wrote the paper. Xiuhe Lv edited the paper. Shilei Wen, Huan Tong contributed to the sample analysis. Chengwei Tang supervised the study.

\section{Acknowledgment}

The authors gratefully acknowledge financial support by National Natural Science Foundation of China (Grant no. 81170413, Grant no. 81400637).

\section{References}

[1] S. A. Bustin, "Absolute quantification of mRNA using real-time reverse transcription polymerase chain reaction assays," Journal of Molecular Endocrinology, vol. 25, no. 2, pp. 169-193, 2000.

[2] A. Giulietti, L. Overbergh, D. Valckx, B. Decallonne, R. Bouillon, and C. Mathieu, "An overview of real-time quantitative PCR: applications to quantify cytokine gene expression," Methods, vol. 25, no. 4, pp. 386-401, 2001.

[3] A. Radonić, S. Thulke, I. M. Mackay, O. Landt, W. Siegert, and A. Nitsche, "Guideline to reference gene selection for quantitative real-time PCR," Biochemical and Biophysical Research Communications, vol. 313, no. 4, pp. 856-862, 2004.

[4] J. G. Norman, G. W. Fink, C. Sexton, and G. Carter, "Transgenic animals demonstrate a role for the IL-1 receptor in regulating IL$1 \beta$ gene expression at steady-state and during the systemic stress induced by acute pancreatitis," The Journal of Surgical Research, vol. 63, no. 1, pp. 231-236, 1996.

[5] I. S. Lossos, D. K. Czerwinski, M. A. Wechser, and R. Levy, "Optimization of quantitative real-time RT-PCR parameters for the study of lymphoid malignancies," Leukemia, vol. 17, no. 4, pp. 789-795, 2003.

[6] C. A. Pérez-Novo, C. Claeys, F. Speleman, P. Van Cauwenberge, C. Bachert, and J. Vandesompele, "Impact of RNA quality on reference gene expression stability," BioTechniques, vol. 39, no. 1, pp. 52-54, 2005.

[7] M. L. Wong and J. F. Medrano, "Real-time PCR for mRNA quantitation," BioTechniques, vol. 39, no. 1, pp. 75-85, 2005.

[8] J. Huggett, K. Dheda, S. Bustin, and A. Zumla, "Real-time RTPCR normalisation; strategies and considerations," Genes and Immunity, vol. 6, no. 4, pp. 279-284, 2005.

[9] C. Tricarico, P. Pinzani, S. Bianchi et al., "Quantitative real-time reverse transcription polymerase chain reaction: normalization to rRNA or single housekeeping genes is inappropriate for human tissue biopsies," Analytical Biochemistry, vol. 309, no. 2, pp. 293-300, 2002.
[10] P. Bhatia, W. R. Taylor, A. H. Greenberg, and J. A. Wright, "Comparison of glyceraldehyde-3-phosphate dehydrogenase and 28S-ribosomal RNA gene expression as RNA loading controls for northern blot analysis of cell lines of varying malignant potential," Analytical Biochemistry, vol. 216, no. 1, pp. 223-226, 1994.

[11] H. Zhong and J. W. Simons, "Direct comparison of GAPDH, $\beta$ actin, cyclophilin, and 28S rRNA as internal standards for quantifying RNA levels under hypoxia," Biochemical and Biophysical Research Communications, vol. 259, no. 3, pp. 523-526, 1999.

[12] T. D. Schmittgen and B. A. Zakrajsek, "Effect of experimental treatment on housekeeping gene expression: validation by real-time, quantitative RT-PCR," Journal of Biochemical and Biophysical Methods, vol. 46, no. 1-2, pp. 69-81, 2000.

[13] O. Thellin, W. Zorzi, B. Lakaye et al., "Housekeeping genes as internal standards: use and limits," Journal of Biotechnology, vol. 75, no. 2-3, pp. 291-295, 1999.

[14] T. Suzuki, P. J. Higgins, and D. R. Crawford, "Control selection for RNA quantitation," BioTechniques, vol. 29, no. 2, pp. 332-337, 2000.

[15] H. J. M. de Jonge, R. S. N. Fehrmann, E. S. J. M. de Bont et al., "Evidence based selection of housekeeping genes," PLoS ONE, vol. 2, no. 9, article e898, 2007.

[16] J. Vandesompele, K. De Preter, F. Pattyn et al., "Accurate normalization of real-time quantitative RT-PCR data by geometric averaging of multiple internal control genes," Genome Biology, vol. 3, no. 7, 2002.

[17] P. D. Lee, R. Sladek, C. M. T. Greenwood, and T. J. Hudson, "Control genes and variability: absence of ubiquitous reference transcripts in diverse mammalian expression studies," Genome Research, vol. 12, no. 2, pp. 292-297, 2002.

[18] M. Kojima, T. Ito, T. Oono et al., "VIP attenuation of the severity of experimental pancreatitis is due to VPAC1 receptor-mediated inhibition of cytokine production," Pancreas, vol. 30, no. 1, pp. 62-70, 2005.

[19] K. Suyama, M. Ohmuraya, M. Hirota et al., "C/EBP homologous protein is crucial for the acceleration of experimental pancreatitis," Biochemical and Biophysical Research Communications, vol. 367, no. 1, pp. 176-182, 2008.

[20] H. Yamada, D. Chen, H.-J. Monstein, and R. Håkanson, "Effects of fasting on the expression of gastrin, cholecystokinin, and somatostatin genes and of various housekeeping genes in the pancreas and upper digestive tract of rats," Biochemical and Biophysical Research Communications, vol. 231, no. 3, pp. 835838, 1997.

[21] M. I. Vaccaro, A. Ropolo, D. Grasso et al., "Pancreatic acinar cells submitted to stress activate TNF- $\alpha$ gene expression," Biochemical and Biophysical Research Communications, vol. 268, no. 2, pp. 485-490, 2000.

[22] J. Jaworek, B. Jachimczak, R. Tomaszewska et al., "Protective action of lipopolysaccharidesin rat caerulein-induced pancreatitis: role of nitric oxide," Digestion, vol. 62, no. 1, pp. 1-13, 2000.

[23] B. Zhong, Q. Zhou, D. M. Toivola, G.-Z. Tao, E. Z. Resurreccion, and M. B. Omary, "Organ-specific stress induces mouse pancreatic keratin overexpression in association with NF- $\kappa \mathrm{B}$ activation," Journal of Cell Science, vol. 117, no. 9, pp. 1709-1718, 2004.

[24] N. Matsuda, J. Nishihira, Y. Takahashi, O. Kemmotsu, and Y. Hattori, "Role of macrophage migration inhibitory factor in acute lung injury in mice with acute pancreatitis complicated by endotoxemia," American Journal of Respiratory Cell and Molecular Biology, vol. 35, no. 2, pp. 198-205, 2006. 
[25] K. A. Haanes, J. M. Kowal, G. Arpino et al., "Role of vesicular nucleotide transporter VNUT (SLC17A9) in release of ATP from AR42J cells and mouse pancreatic acinar cells," Purinergic Signalling, vol. 3, pp. 431-440, 2014.

[26] Y.-Z. Wang, Y.-C. Zhang, J.-S. Cheng et al., "Protective effects of BML-111 on cerulein-induced acute pancreatitis-associated lung injury via activation of Nrf2/ARE signaling pathway," Inflammation, vol. 37, no. 4, pp. 1120-1133, 2014.

[27] T. Hayashi, Y. Ishida, A. Kimura, Y. Iwakura, N. Mukaida, and T. Kondo, "IFN- $\gamma$ protects cerulein-induced acute pancreatitis by repressing NF- $\kappa \mathrm{B}$ activation," Journal of Immunology, vol. 178, no. 11, pp. 7385-7394, 2007.

[28] A. Zabel-Langhennig, B. Holler, K. Engeland, and J. Mössner, "Cyclooxygenase-2 transcription is stimulated and amylase secretion is inhibited in pancreatic acinar cells after induction of acute pancreatitis," Biochemical and Biophysical Research Communications, vol. 265, no. 2, pp. 545-549, 1999.

[29] K. Shimizu, K. Shiratori, T. Sawada et al., "Recombinant human interleukin-11 decreases severity of acute necrotizing pancreatitis in mice," Pancreas, vol. 21, no. 2, pp. 134-140, 2000.

[30] X.-P. Wang, L.-Y. Wu, K. Wu, R.-L. Zhang, and Y.-W. Dong, "The role of lipopolysacchride-binding protein in the pathogenesis of animal model of acute necrotizing pancreatitis," Zhonghua $Y i$ Xue Za Zhi, vol. 83, no. 18, pp. 1619-1623, 2003.

[31] A. M. Song, L. Bhagat, V. P. Singh, G. G. D. Van Acker, M. L. Steer, and A. K. Saluja, "Inhibition of cyclooxygenase2 ameliorates the severity of pancreatitis and associated lung injury," The American Journal of Physiology-Gastrointestinal and Liver Physiology, vol. 283, no. 5, pp. G1166-G1174, 2002.

[32] A. Silva, A. Weber, M. Bain et al., "COX-2 is not required for the development of murine chronic pancreatitis," American Journal of Physiology-Gastrointestinal and Liver Physiology, vol. 300, no. 6, pp. G968-G975, 2011.

[33] S. J. P. Gobin, P. Biesta, and P. J. Van den Elsen, "Regulation of human $\beta 2$-microglobulin transactivation in hematopoietic cells," Blood, vol. 101, no. 8, pp. 3058-3064, 2003.

[34] C. Moreno, C. Nicaise, T. Gustot et al., "Chemokine receptor CCR5 deficiency exacerbates cerulein-induced acute pancreatitis in mice," American Journal of Physiology-Gastrointestinal and Liver Physiology, vol. 291, no. 6, pp. G1089-G1099, 2006.

[35] R. Jesnowski, C. Backhaus, J. Ringel, and M. Löhr, "Ribosomal highly basic $23-\mathrm{kDa}$ protein as a reliable standard for gene expression analysis," Pancreatology, vol. 2, no. 4, pp. 421-424, 2002.

[36] A. Mogal and S. A. Abdulkadir, "Effects of Histone Deacetylase Inhibitor (HDACi); Trichostatin-A (TSA) on the expression of housekeeping genes," Molecular and Cellular Probes, vol. 20, no. 2, pp. 81-86, 2006.

[37] M. U. Cinar, M. A. Islam, M. Pröll et al., "Evaluation of suitable reference genes for gene expression studies in porcine PBMCs in response to LPS and LTA," BMC Research Notes, vol. 6, article 56, 2013.

[38] C. Niederau, L. D. Ferrell, and J. H. Grendell, "Caeruleininduced acute necrotizing pancreatitis in mice: protective effects of proglumide, benzotript, and secretin," Gastroenterology, vol. 88, no. 5, part 1, pp. 1192-1204, 1985.

[39] C. Jin and J.-C. Li, "A mouse model of severe acute pancreatitis induced by caerulein plus lipopolysaccharide," Zhongguo Yi Xue Ke Xue Yuan Xue Bao, vol. 24, no. 4, pp. 393-396, 2002.

[40] K. C. Chao, K. F. Chao, C. C. Chuang, and S. H. Liu, "Blockade of interleukin 6 accelerates acinar cell apoptosis and attenuates experimental acute pancreatitis in vivo," British Journal of Surgery, vol. 93, no. 3, pp. 332-338, 2006.

[41] D. Li, W. Ren, X. Wang et al., "A modified method using TRIzol ${ }^{\circledR}$ reagent and liquid nitrogen produces high-quality RNA from rat pancreas," Applied Biochemistry and Biotechnology, vol. 158, no. 2, pp. 253-261, 2009.

[42] C. L. Andersen, J. L. Jensen, and T. F. Ørntoft, "Normalization of real-time quantitative reverse transcription-PCR data: a modelbased variance estimation approach to identify genes suited for normalization, applied to bladder and colon cancer data sets," Cancer Research, vol. 64, no. 15, pp. 5245-5250, 2004.

[43] M. W. Pfaffl, A. Tichopad, C. Prgomet, and T. P. Neuvians, "Determination of stable housekeeping genes, differentially regulated target genes and sample integrity: bestKeeper-excelbased tool using pair-wise correlations," Biotechnology Letters, vol. 26, no. 6, pp. 509-515, 2004.

[44] N. Silver, S. Best, J. Jiang, and S. L. Thein, "Selection of housekeeping genes for gene expression studies in human reticulocytes using real-time PCR," BMC Molecular Biology, vol. 7, article 33, 2006.

[45] D. Chen, X. Pan, P. Xiao, M. A. Farwell, and B. Zhang, "Evaluation and identification of reliable reference genes for pharmacogenomics, toxicogenomics, and small RNA expression analysis," Journal of Cellular Physiology, vol. 226, no. 10, pp. 2469-2477, 2011.

[46] W. R. Vorachek, Hugejiletu, G. Bobe, and J. A. Hall, "Reference gene selection for quantitative PCR studies in sheep neutrophils,' International Journal of Molecular Sciences, vol. 14, no. 6, pp. 11484-11495, 2013.

[47] S. A. Bustin, V. Benes, J. A. Garson et al., “The MIQE guidelines: minimum information for publication of quantitative real-time PCR experiments," Clinical Chemistry, vol. 55, no. 4, pp. 611-622, 2009.

[48] S. Yuan, L. Rosenberg, A. Ilieva, D. Agapitos, and W. P. Duguid, "Early changes of gene expression during cerulein supramaximal stimulation," Pancreas, vol. 19, no. 1, pp. 45-50, 1999.

[49] S. Selvey, E. W. Thompson, K. Matthaei, R. A. Lea, M. G. Irving, and L. R. Griffiths, " $\beta$-Actin-an unsuitable internal control for RT-PCR," Molecular and Cellular Probes, vol. 15, no. 5, pp. 307311, 2001.

[50] W. Ruan and M. Lai, "Actin, a reliable marker of internal control?” Clinica Chimica Acta, vol. 385, no. 1-2, pp. 1-5, 2007.

[51] C. Rubie, K. Kempf, J. Hans et al., "Housekeeping gene variability in normal and cancerous colorectal, pancreatic, esophageal, gastric and hepatic tissues," Molecular and Cellular Probes, vol. 19, no. 2, pp. 101-109, 2005.

[52] B. Zhong, Q. Zhou, D. M. Toivola, G.-Z. Tao, E. Z. Resurreccion, and M. B. Omary, "Organ-specific stress induces mouse pancreatic keratin overexpression in association with NF- $\kappa \mathrm{B}$ activation," Journal of Cell Science, vol. 117, no. 9, pp. 1709-1719, 2004.

[53] E. L. Calvo, C. Boucher, Z. Coulombe, and J. Morisset, "Pancreatic GAPDH gene expression during ontogeny and acute pancreatitis induced by caerulein," Biochemical and Biophysical Research Communications, vol. 235, no. 3, pp. 636-640, 1997.

[54] D. Andrés, I. Sánchez-Reus, M. Bautista, and M. Cascales, "Depletion of Kupffer cell function by gadolinium chloride attenuates thioacetamide-induced hepatotoxicity. Expression of metallothionein and HSP70," Biochemical Pharmacology, vol. 66, no. 6, pp. 917-926, 2003. 
[55] S. Javorschi, S. Labrouche, and G. Freyburger, "Tissue factor mRNA quantitation without prior monocyte isolation," Biotechniques, vol. 28, no. 6, pp. 1116-1122, 2000.

[56] E. M. Glare, M. Divjak, M. J. Bailey, and E. H. Walters, “ $\beta$ Actin and GAPDH housekeeping gene expression in asthmatic airways is variable and not suitable for normalising mRNA levels," Thorax, vol. 57, no. 9, pp. 765-770, 2002.

[57] K. M. Curtis, L. A. Gomez, C. Rios et al., "EF1 $\alpha$ and RPL13a represent normalization genes suitable for RT-qPCR analysis of bone marrow derived mesenchymal stem cells," BMC Molecular Biology, vol. 11, article 61, 2010.

[58] F. G. Quiroz, O. M. Posada, D. Gallego-Perez et al., "Housekeeping gene stability influences the quantification of osteogenic markers during stem cell differentiation to the osteogenic lineage," Cytotechnology, vol. 62, no. 2, pp. 109-120, 2010.

[59] D. Studer, S. Lischer, W. Jochum, M. Ehrbar, M. Zenobi-Wong, and K. Maniura-Weber, "Ribosomal protein L13a as a reference gene for human bone marrow-derived mesenchymal stromal cells during expansion, adipo-, chondro-, and osteogenesis," Tissue Engineering_Part C: Methods, vol. 18, no. 10, pp. 761-771, 2012. 


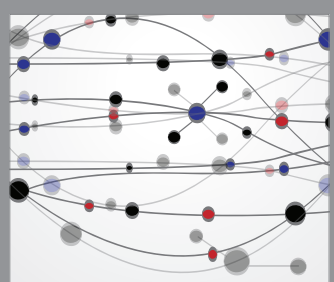

The Scientific World Journal
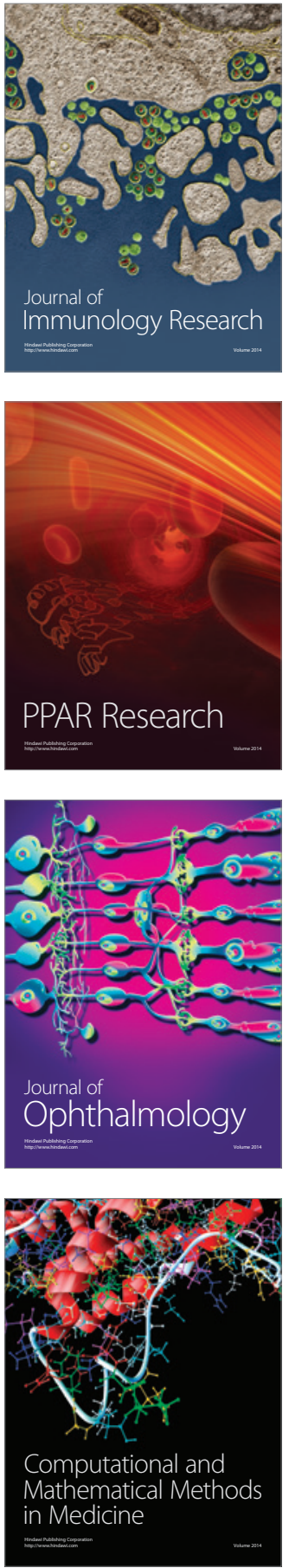

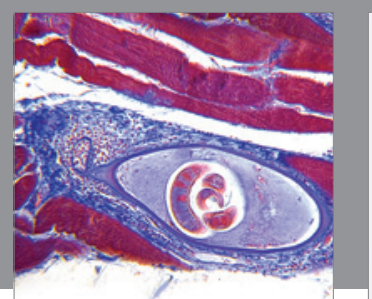

Gastroenterology Research and Practice

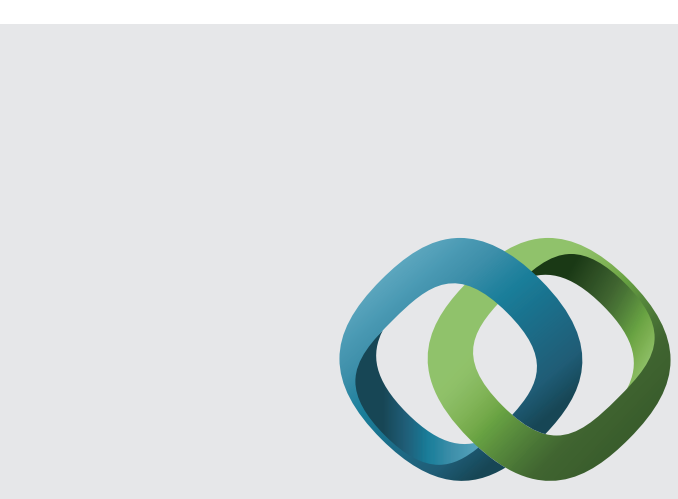

\section{Hindawi}

Submit your manuscripts at

http://www.hindawi.com
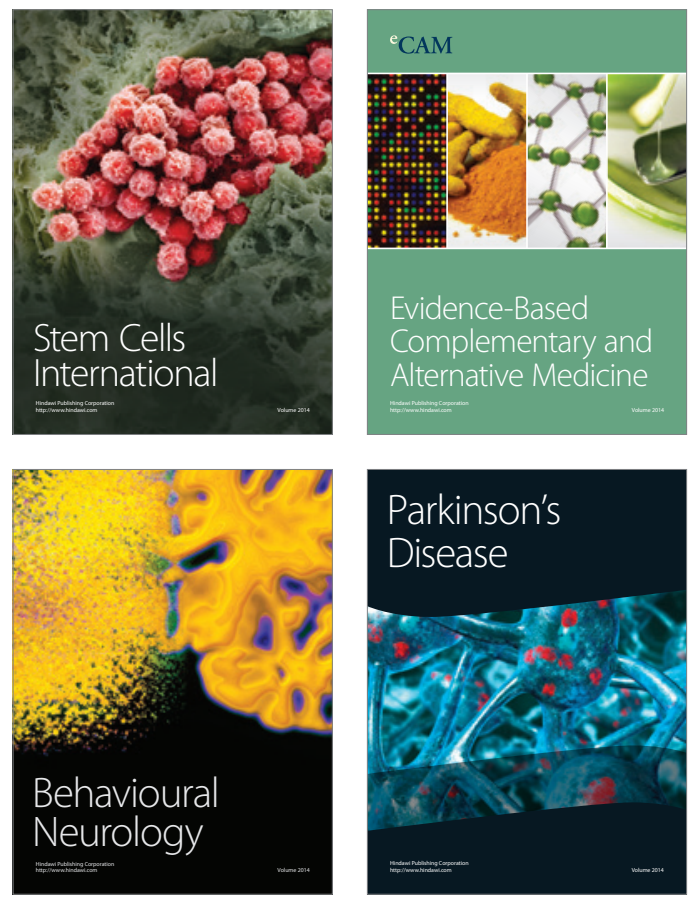
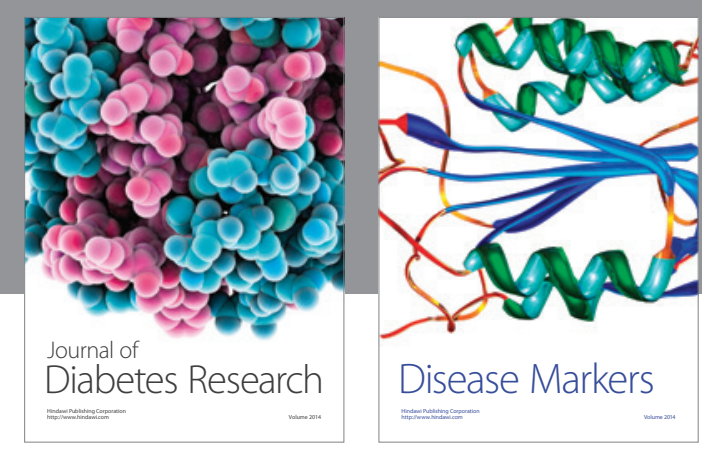

Disease Markers
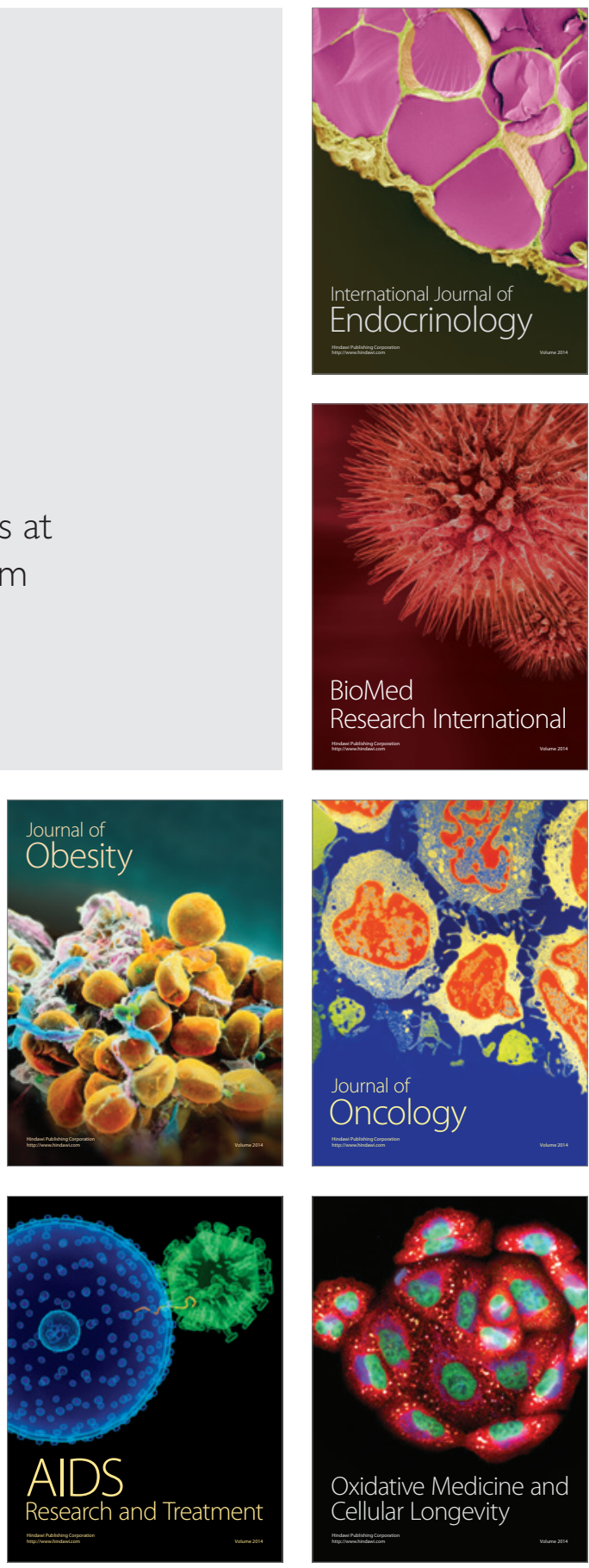